\title{
Identification and Partial Characterization of an L-Tyrosine Aminotransferase (TAT) from Arabidopsis thaliana
}

\author{
Pranav R. Prabhu and André O. Hudson \\ School of Biological and Medical Sciences, Rochester Institute of Technology, 85 Lomb Memorial Drive, \\ Rochester, NY 14623-5603, USA \\ Correspondence should be addressed to André O. Hudson, aohsbi@rit.edu
}

Received 20 April 2010; Accepted 17 June 2010

Academic Editor: Robert Pike

Copyright ( 2010 P. R. Prabhu and A. O. Hudson. This is an open access article distributed under the Creative Commons Attribution License, which permits unrestricted use, distribution, and reproduction in any medium, provided the original work is properly cited.

\begin{abstract}
The aminotransferase gene family in the model plant Arabidopsis thaliana consists of 44 genes. Twenty six of these enzymes are classified as characterized meaning that the reaction(s) that the enzyme catalyzes are documented using experimental means. The remaining 18 enzymes are uncharacterized and are therefore deemed putative. Our laboratory is interested in elucidating the function(s) of the remaining putative aminotransferase enzymes. To this end, we have identified and partially characterized an aminotransferase (TAT) enzyme from Arabidopsis annotated by the locus tag At5g36160. The full-length cDNA was cloned and the purified recombinant enzyme was characterized using in vitro and in vivo experiments. In vitro analysis showed that the enzyme is capable of interconverting L-Tyrosine and 4-hydroxyphenylpyruvate, and L-Phenylalanine and phenylpyruvate. In vivo analysis by functional complementation showed that the gene was able to complement an E. coli with a background of aminotransferase mutations that confers auxotrophy for L-Tyrosine and L-Phenylalanine.
\end{abstract}

\section{Introduction}

Aminotransferases (EC 2.6.1.x) are ubiquitous enzymes that catalyze the reversible interconversion of amino acids and their 2-oxoacid cognates. An amino acid usually serves as the amino donor while a 2-oxoacid serves as the amino acceptor. Aminotransferases are involved in a number of metabolic pathways including the anabolism and catabolism of amino acids, vitamin biosynthesis, carbon and nitrogen assimilation, secondary metabolism, and gluconeogenesis among others [1]. The cofactor pyridoxal-5'-phosphate (PLP) is necessary for aminotransferase activity. Pyridoxal5 -phosphate is covalently bound to the enzyme through an imine linkage to the $\varepsilon$-amino group of conserved lysine residue in the active site of the enzyme [2]. All aminotransferases employ a ping-pong (double displacement) mechanism of action. In the first step, the amino acid substrate is converted to a 2-oxoacid cognate and in the second step; the 2-oxoacid substrate is converted to its cognate amino acid.
In the model organism Arabidopsis thaliana, there are 44 annotated aminotransferases and it was reported that only 25 of the 44 annotated aminotransferase enzymes have been characterized, meaning that the reactions catalyzed by the enzymes have been shown through experimental means [2]. The remaining 19 enzymes are classified as uncharacterized and as such are deemed putative. Recently, one of the uncharacterized enzymes annotated by the locus tag At4g33680 was characterized and was shown to be a $L, L$ diaminopimelate aminotransferase (EC 2.6.1.83) involved in a variant lysine biosynthetic pathway in plants and bacteria [3-5].

In Arabidopsis, there are 7 annotated tyrosine aminotransferases (TATs) (EC 2.6.1.5) which represent $16 \%$ of all aminotransferases. Out of the 7 predicted TATs from Arabidopsis, only two of them have been identified as having TAT activity: At4g23600 [6] and At2g20610 [7].

In E. coli, the aromatic amino acids L-Tyrosine, LPhenylalanine and L-Tryptophan are all synthesized from the common intermediate chorismate (Figure 1(a)). The 
bifunctional enzyme, chorismate mutase (EC 5.4.99.5)/ prephenate dehydratase (EC 4.2.1.51) encoded by the pheA gene catalyzes the conversion of chorismate to prephenate and prephenate to phenylpyruvate. For LTyrosine biosynthesis, the bifunctional enzyme chorismate mutase/prephenate dehydrogenase (EC 5.4.99.5) encoded by the tyrA gene catalyzes the conversion of chorismate to 4-hydroxyphenylpyruvate. The enzyme TAT encoded by the $t y r B$ gene catalyzes the ultimate step in L-Tyrosine and L-Phenylalanine biosynthesis by the conversion of 4hydroxyphenylpyruvate and phenylpyruvate to L-Tyrosine and L-Phenylalanine, respectively (Figure 1(a)). It should be noted that the aspartate aminotransferase (AspC) and the branched-chain aminotransferase (IlvE) are also involved in L-Tyrosine and L-Phenylalanine biosynthesis due to the fact that these enzymes have overlapping activities with TyrB from E. coli and P. aeruginosa [8-10].

In plants, the anabolism of L-Tyrosine and L-Phenylalanine biosynthesis proceeds through the intermediate chorismate. However, the pathway is distinctive from fungi and enteric bacteria in that plants have the amino transfer step at the penultimate step rather than the ultimate step. Chorismate is converted to prephenate by the enzyme chorismate mutase (EC 5.4.99.5) followed by a glutamatedependent amino transfer reaction of prephenate catalyzed by prephenate aminotransferase (EC 2.6.1.79). L-Arogenate, the result of the amino transfer reaction, is either oxidized by the oxidoreductase enzyme arogenate dehydrogenase (EC 1.3.1.43) to form L-Tyrosine or converted to L-Phenylalanine by the lyase enzyme arogenate dehydratase (EC 4.2.1.91) (Figure 1(b)) [11-14].

Plants are known to synthesize the three aromatic amino acids within the plastids [15]. However, a cytosolic chorismate mutase has been identified in Opium poppy [16], Tobacco [17], and Arabidopsis [18]. Although the presence of a cytosolic postchorismate portion of the pathway is still debated, a recent report showed that the key enzymes, arogenate dehydrogenase, and arogenate dehydratase, involved in the synthesis of both L-Tyrosine and L-Phenylalanine, are localized within the plastids of Arabidopsis [19].

Here we present the identification and characterization of a TAT from Arabidopsis annotated by the locus tag At5g36160 that is deemed putative in the public databases. The cDNA was cloned and the purified recombinant enzyme was characterized by performing in vivo and in vitro experiments. Functional complementation analysis demonstrated that the gene is able to complement an E. coli tyrB mutant that confers auxotrophy for both LTyrosine and L-Phenylalanine. In vitro analysis showed that the enzyme was able to interconvert L-Tyrosine and 4-hydroxyphenylpyruvate and L-Phenylalanine and phenylpyruvate.

\section{Material and Methods}

2.1. Plant Growth and Conditions. Arabidopsis thaliana Col 7 Arabidopsis Biological Resource Center (ABRC) was grown on Murashige and Skoog (MS) medium in a growth chamber with a 16-hour light and an 8-hour dark period. The temperature was $24^{\circ} \mathrm{C}$ during the light period and $20^{\circ} \mathrm{C}$ during the dark. The light intensity was approximately $120 \mu \mathrm{E} \mathrm{M}^{-2} \sec ^{-1}$.

2.2. RNA Isolation from Arabidopsis thaliana. Total RNA was isolated from 7 day old Col 7 Arabidopsis seedlings using TriZol reagent (Life Technologies). One hundred milligrams of seedlings was ground in liquid nitrogen and homogenized in $1 \mathrm{~mL}$ of TriZol, followed by incubation at room temperature for two minutes. Total RNA was precipitated using $1 \mathrm{~mL} 100 \%(\mathrm{v} / \mathrm{v})$ isopropanol. The RNA pellet was washed three times with $1 \mathrm{~mL} \mathrm{75 \%} \mathrm{(v/v)} \mathrm{ethanol.}$ The RNA pellet was air-dried and resuspended in $30 \mu \mathrm{L}$ of Diethyl Pyrocarbonate- (DEPC-) treated water.

2.3. cDNA Synthesis. Total RNA isolated from Col 7 Arabidopsis seedlings was used to synthesize cDNA. The reaction contained $1 \mu \mathrm{L}$ oligo $(\mathrm{dT})_{12-18}$ primer, $1 \mu \mathrm{g}$ total RNA, $1 \mu \mathrm{L}$ of $10 \mathrm{mM}$ dNTP mix, and DEPC-treated water up to $13 \mu \mathrm{L}$. The mixture was incubated at $65^{\circ} \mathrm{C}$ for 5 minutes, followed by incubation on ice for 5 minutes. The Reverse Transcription System Kit (Promega) was used to synthesize cDNA following the manufacturer's protocol.

2.4. Amplification and Cloning of the At5g36160 cDNA. The full-length cDNA of At5g36160 was amplified by PCR. The cDNA was amplified using twelve picomoles of forward and reverse primers, $1 \mathrm{mM} \mathrm{MgSO}_{4}, 0.5 \mathrm{mM}$ of each of the four deoxynucleotide triphosphates, $2 \mu \mathrm{L}$ of cDNA product, and 1 unit of Platinum Pfx DNA polymerase (Invitrogen) using the following PCR conditions: 1 cycle at $94^{\circ} \mathrm{C}$ for 2 minutes, followed by 36 cycles of $94^{\circ} \mathrm{C}$ for 15 seconds, $60^{\circ} \mathrm{C}$ for 30 seconds, and $72^{\circ} \mathrm{C}$ for 2 minutes. The forward and reverse primers used to amplify the gene were $5^{\prime}$ CCCCGAATTCATGGGAGAAAACGGAGCCAAGCGAT-3' and $5^{\prime}$-CCCCGAGCTCTCATGGCTGATTCTTGGAGTGTCTC- $3^{\prime}$.

The underlined sequence represents the restriction enzyme sites used in the cloning of the cDNA while the bolded and italicized sequences represent initiation and termination codons. For cloning, the PCR fragment was digested with EcoRI and SacI and ligated into the plasmid pET30a (Novagen) to produce the plasmid pET30a + At5g36160. The recombinant protein derived from this plasmid carries a hexahistidine and S-TAG epitope derived from pET30a plasmid at the amino terminus. To confirm the fidelity of the PCR reaction, the PCR fragment was sequenced from the pET30a construct using the T7 promoter primer $5^{\prime}$-TAATACGACTCACTATAGGG-3' and the T7 terminator primer 5' -TATGCTAGTTATTGCTCAG$3^{\prime}$, and was compared to the published sequence deposited in the public database (http://www.arabidopsis.org/).

2.5. Functional Complementation Plasmid Construct. The plasmid used for functional complementation of the E. coli DL39 mutant was produced by subcloning the XbaI and HindIII fragment from pET30a + At5g36160 into pBAD33 


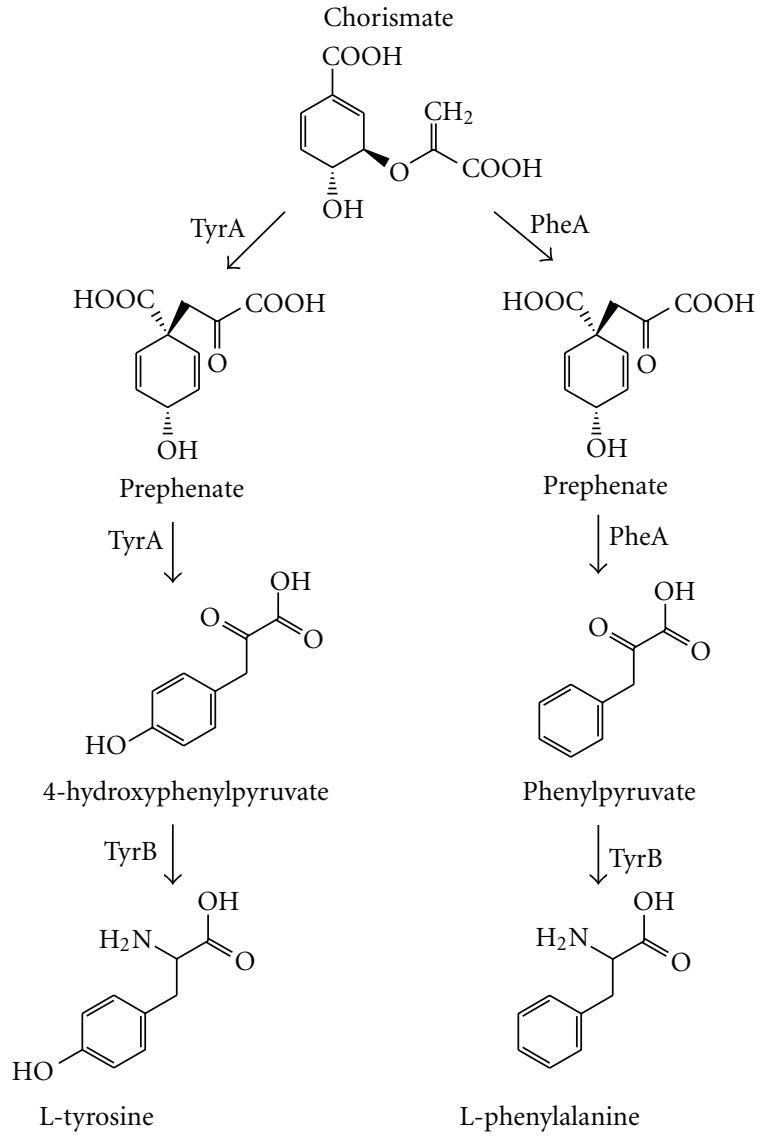

(a)

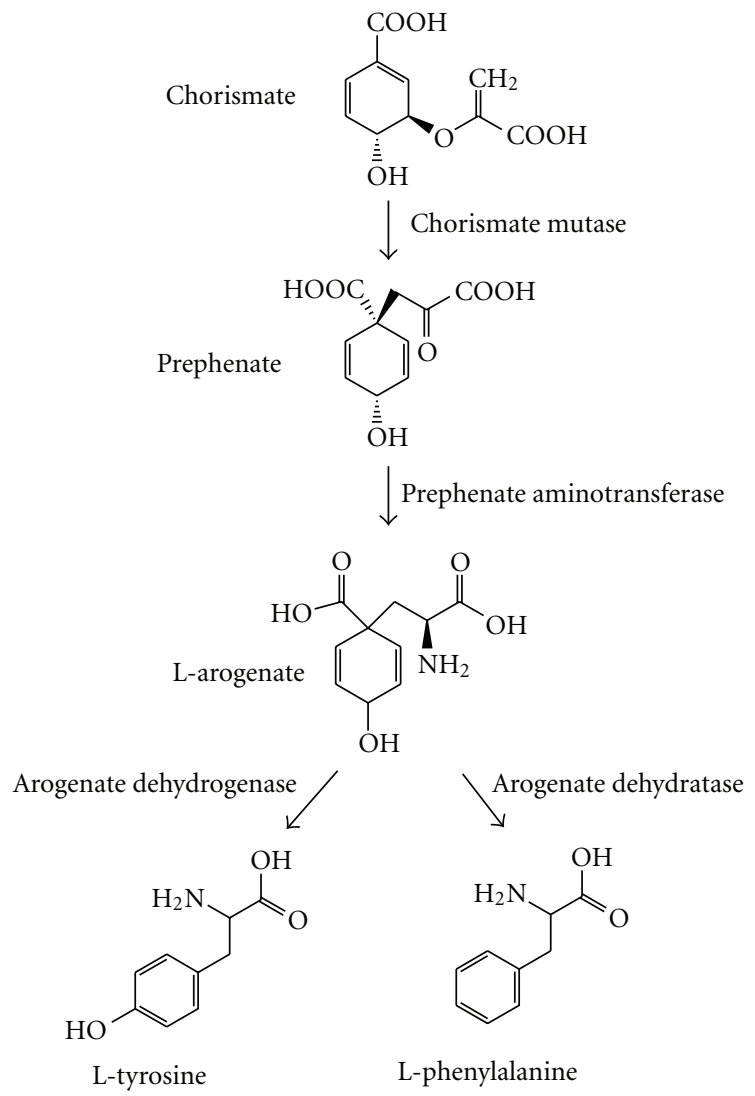

(b)

Figure 1: Pathways for L-Tyrosine and L-Phenylalanine biosynthesis in E. coli and plants. (a) shows the pathway for both amino acids from the intermediate chorismate in E. coli. Abbreviations in the diagram include PheA (chorismate mutase/prephenate dehydratase), TyrA (chorismate mutase, prephenate dehydrogenase), and TyrB (tyrosine aminotransferase). (b) depicts the plant pathway for the synthesis of the amino acids from the common intermediate L-Arogenate.

[20], to produce pBAD33 + At5g36160. The fusion protein produced from the pBAD33 construct is identical to the protein produced from the $\mathrm{pET} 30 \mathrm{a}$ construct.

2.6. Functional Complementation. The E. coli auxotrophic mutant DL39 was obtained from the Coli Genome Stock Center (CGSC) located at Yale University (http://cgsc.biology.yale.edu/). The DL39 strain (no. 6913) has the following genotype (LAM-, aspC13, fnr-25, rph-1 ilvE12, tyrB507) [21]. For functional complementation, the strain was transformed with either pBAD33 or pBAD33 + At5g36160. Colonies were selected on Luria-Bertani (LB) agar plates supplemented with $50 \mu \mathrm{g} \mathrm{mL}^{-1}$ L-Tyrosine, $50 \mu \mathrm{g} \mathrm{mL}^{-1}$ L-Phenylalanine, and $34 \mu \mathrm{g} \mathrm{mL}^{-1}$ chloramphenicol. Fifty individual colonies were then replicated onto M9 agar plates supplemented with $50 \mu \mathrm{g} \mathrm{mL}^{-1}$ L-Phenylalanine and $50 \mu \mathrm{g} \mathrm{mL}^{-1}$ L-Tyrosine, $0.5 \%(\mathrm{w} / \mathrm{v})$ glycerol, $0.2 \%(\mathrm{w} / \mathrm{v})$ arabinose, $50 \mu \mathrm{g} \mathrm{mL}$ L-Aspartate, $50 \mu \mathrm{g} \mathrm{mL}^{-1}$ L-Leucine, $50 \mu \mathrm{g} \mathrm{m}^{-1}$ L-Valine, $50 \mu \mathrm{g} \mathrm{mL}^{-1}$ L-Isoleucine, $10 \mu \mathrm{g} \mathrm{mL}^{-1}$ uracil and also on plates lacking L-Phenylalanine and L-Tyrosine. To test whether the cDNA was able to complement the L-Aspartate and Branched-chain amino acids auxotrophy in DL39, replica-plating was carried out on M9 media supplemented with or without the amino acid(s). The strains were incubated at $30^{\circ} \mathrm{C}$ for 48 hours. The growth curve of DL39 expressing the pBAD33 or pBAD33 + At5g36160 plasmid was carried out by inoculating $50 \mathrm{~mL}$ M9 media supplemented with $0.5 \%(\mathrm{w} / \mathrm{v})$ glycerol, $0.2 \%(\mathrm{w} / \mathrm{v})$ arabinose, $50 \mu \mathrm{g} \mathrm{mL}^{-1}$ L-Aspartate, $50 \mu \mathrm{g} \mathrm{mL}^{-1}$ L-Leucine, $50 \mu \mathrm{g} \mathrm{mL}^{-1}$ L-Valine, $50 \mu \mathrm{g} \mathrm{mL}^{-1}$ L-Isoleucine, and $10 \mu \mathrm{g} \mathrm{mL}^{-1}$ uracil with $1 \mathrm{~mL}$ of overnight culture. The absorbance at $600 \mathrm{~nm}$ was documented at one hour intervals up to 12 hours.

2.7. Protein Expression and Purification. The plasmid pET30a + At5g36160 was transformed into E. coli BL21CodonPlus-RIPL strain (Stratagene). For protein expression and purification, the strain was grown in $1.0 \mathrm{~L} \mathrm{LB}$ broth containing $50 \mu \mathrm{g} \mathrm{mL}^{-1}$ kanamycin and $34 \mu \mathrm{g} \mathrm{m}^{-1}$ chloramphenicol at $37^{\circ} \mathrm{C}$ to an $\mathrm{OD}_{600 \mathrm{~nm}}$ of 0.5 . Protein expression was induced by adding isopropyl $\beta$-D-1thiogalactopyranoside (IPTG) to a final concentration of $0.2 \mathrm{mM}$ at $25^{\circ} \mathrm{C}$ for 5 hours. For purification, the cells were lysed by sonication in a solution of $50 \mathrm{mM}$ sodium phosphate and $300 \mathrm{mM} \mathrm{NaCl}$ (pH 8.0). The soluble protein 


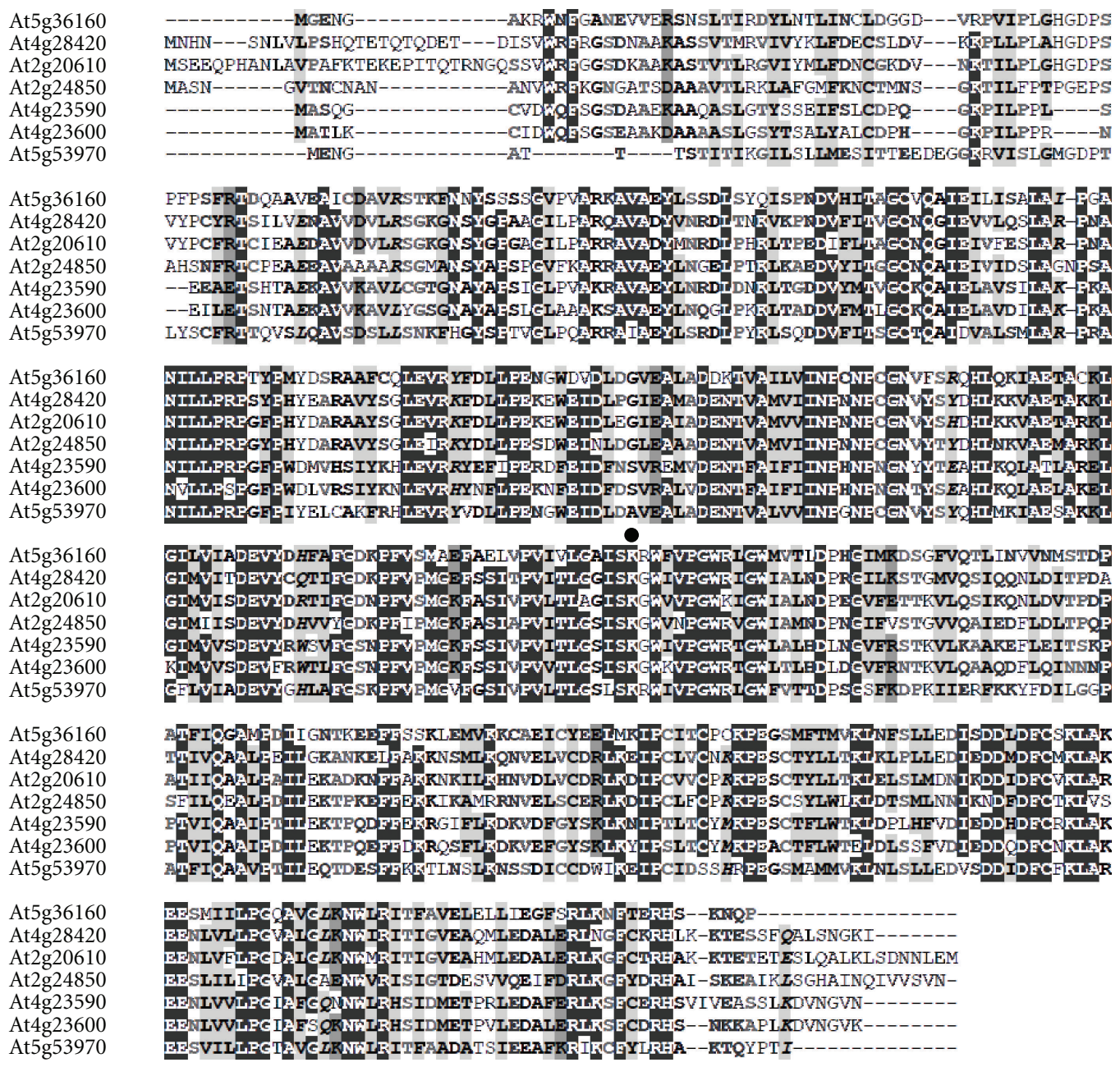

FIgure 2: Amino acid sequence alignment of the TAT family from Arabidopsis. The method used for creating the alignment is described in Section 2. The black circle denotes the PLP ligand at the conserved lysine residue.

extract was incubated with $1.0 \mathrm{~mL}$ bed volume of Talon Metal Affinity Resin (Clontech) for 30 minutes at $4^{\circ} \mathrm{C}$. The resin was washed with $300 \mathrm{~mL}$ of sonication buffer containing $10 \mathrm{mM}$ imidazole ( $\mathrm{pH} 8.0$ ), and the enzyme was eluted using $50 \mathrm{~mL}$ of sonication buffer containing $250 \mathrm{mM}$ imidazole ( $\mathrm{pH}$ 8.0). The purified enzyme was concentrated using an Amicon Ultra 10,000 molecular weight cutoff filter device, replacing the elution buffer with $100 \mathrm{mM}$ HEPES-NaOH containing $1 \mathrm{mM}$ DTT and $1 \mathrm{mM}$ EDTA $(\mathrm{pH}$ 8.2 ). For long-term storage, the enzyme was stored in $50 \%$ $(\mathrm{v} / \mathrm{v})$ glycerol. Protein concentration was measured using the Bradford assay with bovine serum albumin as the standard [22].

2.8. Enzyme Assays. Two different enzyme assays were used to measure TAT activity. The forward assay measured the production of phenylpyruvate and 4-hydroxphenylpyruvate from L-Phenylalanine and L-Tyrosine degradation, respectively. The reverse assay measured the production of 2ketoglutarate from the transamination of phenylpyruvate or 4-hydroxyphenylpyruvate using the coupling enzyme 2ketoglutarate dehydrogenase. For the forward reaction, the standard assay consisted of $10 \mathrm{mM}$ donor (L-Tyrosine or L-Phenylalanine), $10 \mathrm{mM}$ acceptor (2-ketoglutarate, pyruvate, oxaloacetate, oxovalerate, prephenate), and pure recombinant At5g36160 in $100 \mathrm{mM}$ HEPES-NaOH $(\mathrm{pH}$ 8.2 ) buffer in a final volume of $0.4 \mathrm{~mL}$. The reactions were incubated at $30^{\circ} \mathrm{C}$ for 1 hour and $0.1 \mathrm{~mL}$ of $2 \mathrm{~N} \mathrm{NaOH}$ was added to stop the reaction. The production of phenylpyruvate and 4-hydroxyphenylpyruvate was measured at $A_{320}$ and $A_{331}$, respectively, using the extinction coefficient of $17,500 \mathrm{M}^{-1}$ for phenylpyruvate and $32,850 \mathrm{M}^{-1}$ for 4-hydroxyphenylpyruvate [23]. For the reverse reaction, the standard assay consisted of $0.3 \mathrm{mM}$ NAD, $5 \mathrm{mM}$ glutamate, $10 \mathrm{mM}$ phenylpyruvate or 4-hydroxyphenylpyruvate, $0.3 \mathrm{mM}$ CoA, $200 \mu \mathrm{g} \mathrm{2-}$ ketoglutarate dehydrogenase $\left(0.85 \mu \mathrm{mol} \mathrm{min}^{-1} \mathrm{mg}^{-1}\right.$ protein) (Sigma), and pure recombinant At5g36160 in $100 \mathrm{mM}$ HEPES-NaOH ( $\mathrm{pH} 8.2$ ), in a final volume of $0.5 \mathrm{~mL}$. The production of NADH was measured at $A_{340}$. Both the forward and reverse assays were incubated at $30^{\circ} \mathrm{C}$. All 
kinetic constants were calculated using GraphPad Prism V3.03 software by using the nonlinear regression analysis algorithm feature. A Beckman DU640 Spectrophotometer was used to monitor enzyme activity.

2.9. Multiple-Protein Sequence Alignment and Phylogenetic Tree Construction. TAT protein sequences from Arabidopsis were aligned using the program MegAlign (DNAstar) using the ClustalW algorithm. A boxshade representation of the alignment was produced using the Chromatic Representation Of Multiple Alignments (CHROMA) freeware [24]. The accession numbers for the Arabidopsis TATs are presented in Table 1. The phylogenetic tree was constructed by creating a protein alignment using ClustalW and the tree was drawn using the TREEVIEW program [25]. The accession numbers for the bacterial and mammalian enzymes are presented in the tree adjacent to the abbreviated initials for the genus and species of each bacterial TAT (Ec: Escherichia coli, Pa: Pseudomonas aeruginosa, Bp: Bordetella petrii, and Se: Salmonella enterica) and mammalian TAT (Dr: Danio rerio, Xt: Xenopus tropicalis, Hs: Homo sapien, Mm: Mus musculus, and Rn: Rattus norvegicus).

\section{Results and Discussion}

3.1. The Tyrosine Aminotransferase Gene Family in Arabidopsis thaliana. There are 44 annotated aminotransferases in Arabidopsis thaliana [1]. Seven out of the reported 44 enzymes are predicted to encode TATs. The accession numbers, locus tags, and updated annotated information of the TAT are presented in Table 1. Also presented is the information of the E. coli ortholog annotated by the accession number NP_418478. A comparative analysis as it pertains to the amino acid sequence of the enzymes showed that the $E$. coli ortholog is only $7.6 \%$ identical throughout the entire protein sequence when compared to the plant enzyme that is the focus of this study (Table 1). The protein sequence alignment of the seven TATs from Arabidopsis shows that they are fairly conserved (Figure 2). The percent identity ranges from $54.1 \%$ to $38.8 \%$ when the other TAT proteins are compared to At5g36160 (Table 1).

\subsection{The Gene Annotated by the Locus Tag At5g36160 Encodes}

TAT. To assess the function of At5g36160, the cDNA was cloned and the enzyme was purified using affinity chromatography (Figure 3 ). The pure recombinant protein was used to perform enzyme assays to answer the question of whether the enzyme is capable of catabolizing L-Tyrosine and L-Phenylalanine to either 4-hydroxyphenylpyruvate or phenylpyruvate, respectively. Since most aminotransferases are able to catalyze reversible reactions, the enzyme should also be able to synthesize L-Tyrosine and L-Phenylalanine from 4-hydroxyphenylpyruvatre and phenylpyruvate, respectively, given the proper amino donor. In the forward direction, the substrates L-Tyrosine and LPhenylalanine are the amino donors while 2-ketoglutarate is the amino acceptor. In the reverse direction, glutamate serves as the amino donor while 4-hydroxyphenylpyruvate

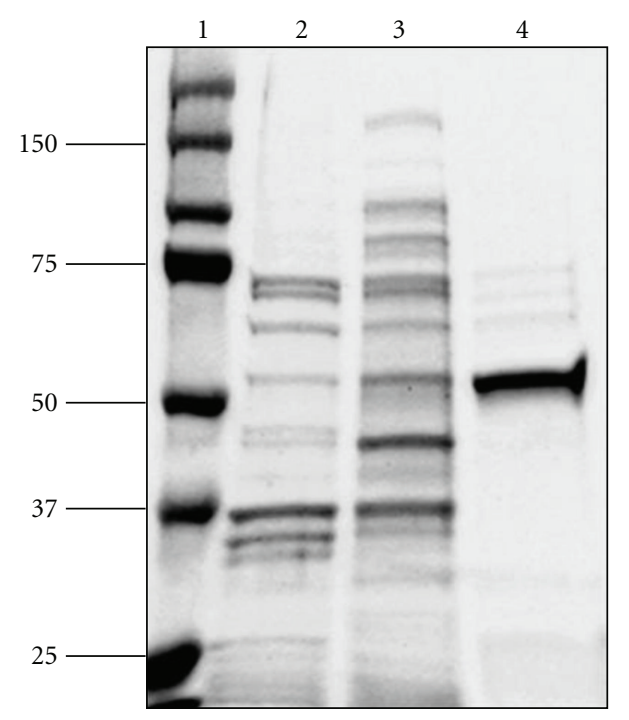

FIgURE 3: Recombinant expression and purification of At5g36160 from the E. coli strain BL21 Codon Plus RIPL. The enzyme was purified as described in Section 2. Along with the molecular mass markers $(\mathrm{kDa})$ (lane 1), the gel shows the profile of $10 \mu \mathrm{g}$ soluble proteins extracted from uninduced (lane 2) and induced cells (lane 3 ). Lane 4 shows the profile of $1.0 \mu \mathrm{g}$ of the purified recombinant enzyme. The proteins were resolved on an SDS-PAGE gel containing $10 \%(\mathrm{w} / \mathrm{v})$ acrylamide, and the gel was stained using Coomassie Blue.

and phenylpyruvate serve as the amino acceptors (Figure 4). Figure 5(a) shows the synthesis of 4-hydroxyphenylpyruvate and phenylpyruvate from the transamination of L-Tyrosine and L-Phenylalanine when increasing amounts of enzyme was added to the assay. The correlation observed for the synthesis of 4-hydroxyphenylpyruvate and phenylpyruvate is consistent with the synthesis of 2-ketoglutarate, which is a coproduct formed by the transamination of these substrates (Figure 5(b)). No enzymatic activity was observed when either the amino donors or the amino acceptors were omitted in the forward and reverse assays (data not shown). Moreover, a mock purification was done using a plasmid only (pET30a) control using the same purification scheme. Enzyme activity was not observed when using the eluate from the mock purification, showing that the activity observed in the forward and reverse assay is from the recombinant enzyme and not from the native E. coli BL21-CodonPlusRIPL TAT enzyme.

3.3. The Gene Annotated by the Locus Tag At5g36160 Is Able to Functionally Complement the E. coli L-Tyrosine and LPhenylalanine Auxotrophic Mutant DL39. Given the fact that the pure recombinant enzyme was able to synthesize LTyrosine and L-Phenylalanine in vitro, it should be possible to complement an E. coli mutant devoid in TAT activity. To confirm this, a functional complementation assay was used because it was previously reported that a TAT from Pseudomonas aeruginosa ( $p h y C$ ) was able to complement the DL39 E. coli mutant [26]. DL39 is a triple mutant that has mutations in the aminotransferase genes aspC (L-Aspartate 
TABle 1: Locus tag and accession numbers for TATs from Arabidopsis and from E. coli. The accession numbers and predicted function for the enzymes were obtained from GenBank ${ }^{\mathrm{TM}}$ (http://www.ncbi.nlm.nih.gov/Genbank/) and from The Arabidopsis Information Resource (TAIR) (http://www.arabidopsis.org/). The closed circle refers to the Arabidopsis plant enzyme that was actually studied and the asterisk denotes the accession number of the E. coli TAT enzyme.

\begin{tabular}{lccc}
\hline Accession number & Locus tag & \% identity to At5g36160 & Annotation in GenBank $^{\mathrm{TM}}$ \\
\hline NP_198465 & At5g36160 & - & Putative tyrosine aminotransferase \\
AAN31921 & At5g53970 & 54.1 & Putative tyrosine aminotransferase \\
CAB79644 & AT4g28420 & 48.3 & Putative tyrosine aminotransferase \\
AAG37061 & At2g20610 & 47.4 & Putative tyrosine aminotransferase \\
AAP31937 & At2g24850 & 44.8 & Tyrosine aminotransferase \\
CAB79314 & AT4g23590 & 39.0 & Putative tyrosine aminotransferase \\
CAB79315 & At4g23600 & 38.8 & Putative tyrosine aminotransferase \\
NP_418478* & b4054 & 7.6 & Tyrosine aminotransferase \\
\hline
\end{tabular}

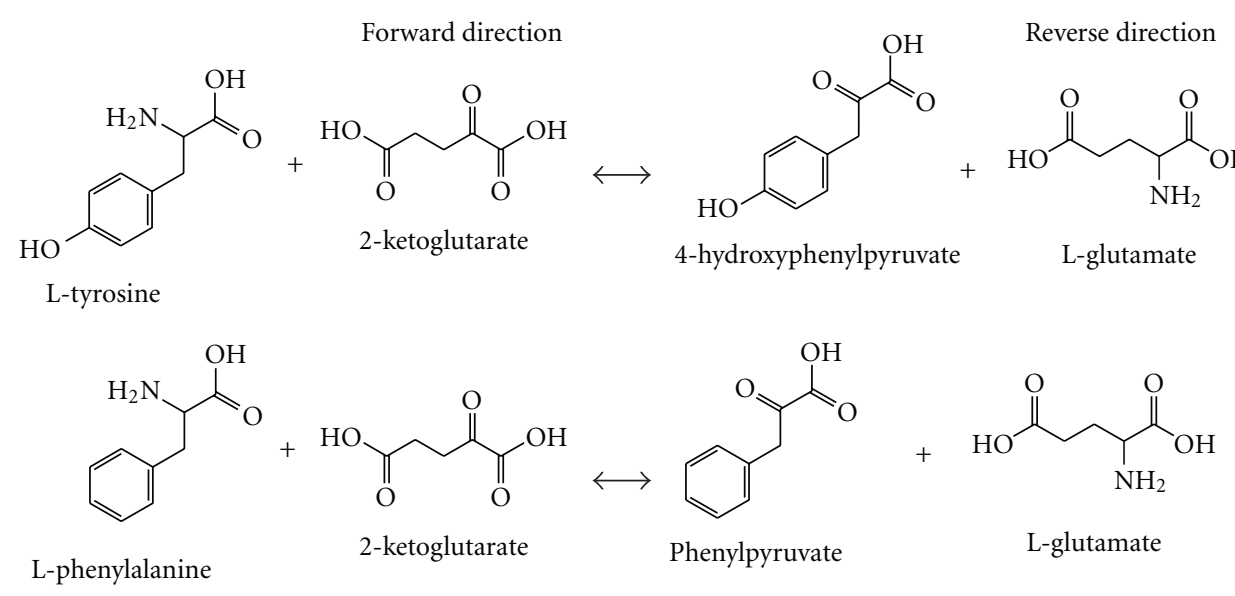

FIgURE 4: Reactions catalyzed by TATs. Reactions catalyzed by the enzyme in the forward and reverse directions. In the forward direction, L-Tyrosine and L-Phenylalanine serve as the amino donors while 2-ketoglutarate serves as the acceptor. In the reverse direction, glutamate serves as the amino donor while 4-hyrdroxyphenylpyruvate and phenylpyruvate serve as the acceptors.

aminotransferase), $\operatorname{tyr} B$ (L-Tyrosine aminotransferase), and $i l v E$ (branched-chain aminotransferase) which have been shown to have overlapping activities in E. coli [26]. As a result of these mutations, the bacterium is auxotrophic for the amino acids L-Aspartate, L-Tyrosine, L-Phenylalanine, and the branched-chain amino acids: L-Leucine, L-Valine, and L-Isoleucine. The DL39 strain was transformed with either an empty plasmid or a plasmid expressing the At5g36160 protein. While the mutant is able to grow on media supplemented with L-Tyrosine and L-Phenylalanine, only the mutant strain expressing the plant enzyme is able to grow on L-Tyrosine and L-Phenylalanine free media (Figure 6(a)). Figure 6(b) shows the graph corresponding to growth curve of the E. coli mutant transformed with the empty plasmid or the plasmid expressing the plant TAT enzyme. Since aminotransferases are known to be promiscuous enzymes, and given the fact that the DL39 E. coli mutant contains a mutation in the branched-chain aminotransferase gene, the growth on media containing L-Tyrosine, L-Phenylalanine, and L-Aspartate but lacking the amino acids L-Leucine, LValine, and L-Isoleucine was tested. The results from this analysis showed that the plant enzyme was not able to functionally complement the branched-chain amino acid auxotrophy in the DL39 E. coli mutant (Figure 6(c)). The DL39 E. coli mutant also harbors a mutation in the aspartate aminotransferase gene $(\operatorname{asp} C)$; the plant enzyme was not able to complement the L-Aspartate auxotrophy using the functional complementation assay (Figure 6(c)). These results indicate that the plant enzyme annotated by the locus tag At5g36160 encodes TAT and it is not involved in the anabolic pathways for L-Leucine, L-Valine, L-Isoleucine, and L-Aspartate. Although the plant enzyme is only $7.6 \%$ identical to the E. coli TAT enzyme, it was able to complement the E. coli mutant. In fact, based on a phylogenetic tree comparing sequence similarity, the plant TATs, bacterial TATs and the mammalian TATs are divergent even though the enzymes are grouped in the same subdivision within the same subgroup of the class I aminotransferases [2, 27, 28]. The sequence similarity between the three groups of TATs is shown in a phylogenetic tree which depicts three distinct clades. Clade A represents the bacterial enzymes from several bacteria; clade B represents a selection of mammalian enzymes, and clade $\mathrm{C}$ represents the Arabidopsis TAT enzyme family (Figure 7). 


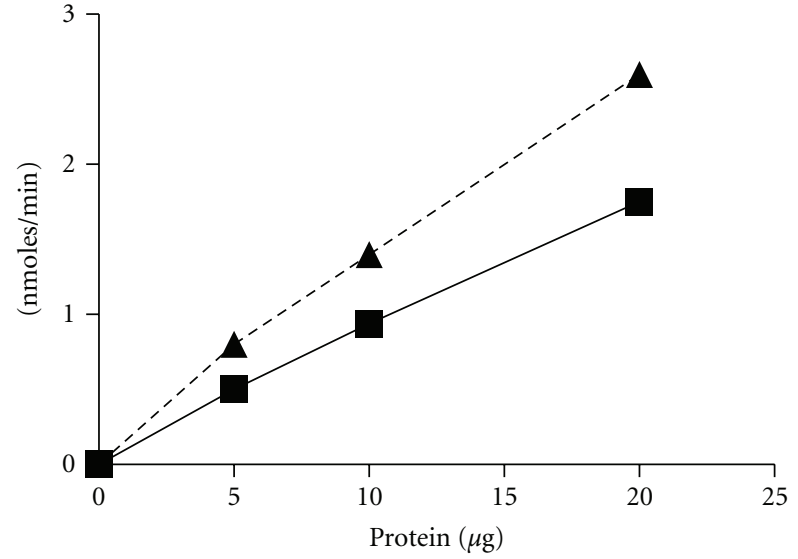

(a)

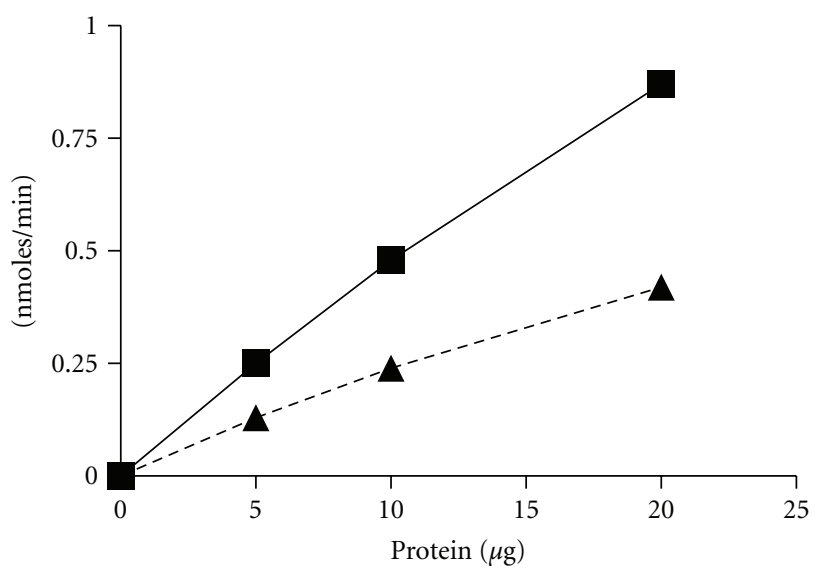

(b)

FIGURE 5: Detection of TAT activity in the forward and reverse directions. Both graphs show the correlation between reaction rate and the amount of enzyme added to the reaction. (a) shows the synthesis of 4-hydroxyphenylpyruvate (square) and phenylpyruvate (triangle) in the forward direction, while (b) shows the synthesis of 2-ketoglutarate synthesized from 4-hyrdoxyphenylpyruvate (square) and phenylpyruvate (triangle) in the reverse direction. The standard assays used for this analysis are described in Section 2.

3.4. Physical Properties of At5g36160: Effects of pH, Temperature on Enzyme Activity. The transamination reaction using the forward assay with L-Tyrosine as the donor and 2-ketoglutarate as the acceptor was carried out at various temperatures and various $\mathrm{pH}$ levels. The enzyme had an optimal activity between the temperature range of 30 $40^{\circ} \mathrm{C}$. The enzyme lost half of its activity at $60^{\circ} \mathrm{C}$ and was inactive at $90^{\circ} \mathrm{C}$ (see Figure 1 (a) in Supplementary Material available online at doi:10.1155/2010/549572). The activity of the pure enzyme was examined using the buffers HEPES$\mathrm{NaOH}$ ranging in $\mathrm{pH}$ values from 6.8-8.2 (Supplementary Figure 1(b)) and TRIS-HCL ranging in values from 7.09.0 (Supplementary Figure 1(c)). Maximum activity was observed when HEPES-NaOH (pH 8.2) was used.

3.5. Subunit Structure of At5g36160. The subunit structure of most aminotransferases is dimeric in nature containing two identical subunits. The molecular weight of aminotransferases in plants ranges between 48,000 Daltons for ornithine aminotransferase in squash [29], to 100,000 Daltons for soybean aspartate aminotransferase [30]. The molecular weight of the pure recombinant TAT was estimated using SDS-PAGE analysis and found to be approximately $52 \mathrm{kDa}$ (Figure 3). If the holoenzyme is active as a dimer, the recombinant At5g36160 is approximately $100 \mathrm{kDa}$ which is consistent with other plant aminotransferases [3]. Moreover, the structure of the E. coli TyrB was solved by X-ray crystallography and the holoenzyme was shown to be homodimeric [31]. It should be noted that we attempted to use size exclusion HPLC to gather information regarding the subunit structure of the recombinant enzyme but the results were not consistent with the SDS-PAGE results due to the multiple oligomerization states of the purified recombinant enzyme. Future experiments using gel filtration chromatography of the native enzyme would be helpful in determining the actual subunit structure of this enzyme.

3.6. Absorption Spectrum Analysis of At5g36160. Aminotransferases require PLP for activity because PLP acts as an electron sink, accepting electrons from substrates [32]. The purified At5g36160 was yellowish in color suggesting that PLP was bound to the enzyme. This was corroborated by UVvisible light wavelength scan analysis. The analysis revealed an absorption peak centered around $410 \mathrm{~nm}$ consistent with the presence of PLP along with a shoulder peak centered around $360 \mathrm{~nm}$ (Figure 8). It should be noted that free PLP has an absorption maximum centered around $390 \mathrm{~nm}$. The detection of the PLP-form from the purified recombinant enzyme is indicative of a Schiff-base linkage with the $\varepsilon$-amino group of a conserved L-Lysine residue at position 252 in the amino acid sequence (Figure 2). This is consistent with other aminotransferase enzymes that have been characterized [3]. Moreover, a comparative protein alignment using At5g36160 and another aminotransferase At4g33680 that was solved by $\mathrm{X}$-ray crystallography showed that the lysine at position 252 is the PLP ligand [33] denoted by the conserved PLP binding motif (data not shown).

3.7. Kinetic Properties of At5g36160. The kinetic properties of the enzyme was tested at several concentrations of one substrate and at the saturation levels of other substrates. The reciprocal plots for all 6 substrates were linear and were consistent with Michaelis-Menten kinetics. The $V_{\max }$ for the forward and reverse directions were calculated along with the apparent $K_{m}$ for the various substrates. The enzyme has a maximum velocity of approximately $5.0 \mu$ moles $\mathrm{min}^{-1} \mathrm{mg}^{-1}$ in the forward direction and $23.5 \mu$ moles $\mathrm{min}^{-1} \mathrm{mg}^{-1}$ in the reverse direction. The apparent $K_{m}$ for the substrates were $0.19 \mathrm{mM}$ for L-Tyrosine, $0.84 \mathrm{mM}$ for LPhenylalanine, $1.2 \mathrm{mM}$ for 2-ketoglutarate, $1.4 \mathrm{mM}$ for L-glutamate, $0.22 \mathrm{mM}$ for 4-hydroxyphenylpyruvate, and $0.13 \mathrm{mM}$ for phenylpyruvate (Table 2(a)). The physical and kinetic properties of the enzyme are similar to the ones reported for the E. coli enzyme [8, 9]. The saturation plots along with the assay conditions that were used to calculate 


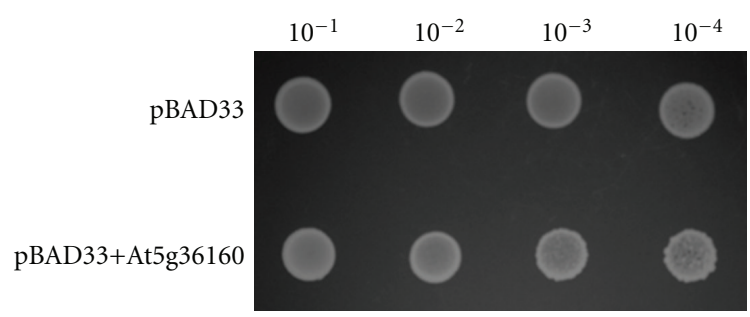

$+\mathrm{Tyr}+\mathrm{Phe}$

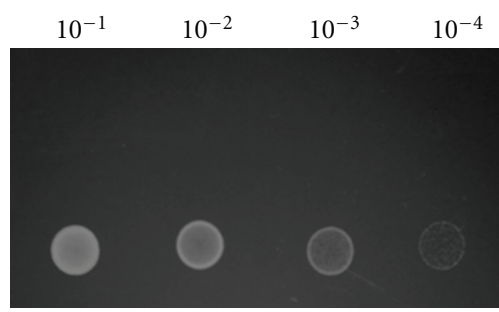

- Tyr - Phe

(a)

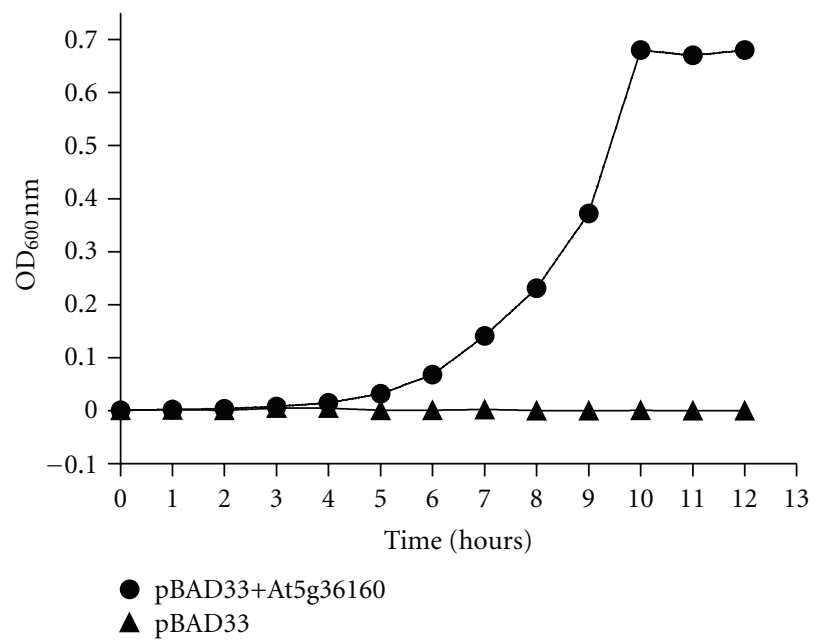

(b)

\begin{tabular}{|c|c|c|c|}
\hline \multicolumn{3}{|c|}{ Amino acid supplementation } & \multirow{2}{*}{$\begin{array}{c}\text { Growth } \\
\text { on M9 media }\end{array}$} \\
\hline L-tyr+L-phe & L-asp & L-Ile+L-leu+L-val & \\
\hline+ & + & + & + \\
\hline- & + & + & + \\
\hline+ & - & + & - \\
\hline+ & + & - & - \\
\hline
\end{tabular}

(c)

FIGURE 6: (a) Functional complementation assay. Functional complementation was tested using the E. coli mutant DL39. The plasmids used were pBAD33 and pBAD33 + At5g36160. The bacteria were grown to an OD of 1.0 measured at $600 \mathrm{~nm}$, the strains were serially diluted to $10^{-1}, 10^{-2}, 10^{-3}$, and $10^{-4}$ using $0.85 \%(\mathrm{w} / \mathrm{v})$ saline, and $5 \mu \mathrm{L}$ was replica plated on medium with or without L-Tyrosine and L-Phenylalanine supplemented with $0.2 \%(\mathrm{w} / \mathrm{v})$ arabinose as described in Section 2. It should be noted that 50 individual transformants were replica plated and tested using the complementation assay. All 50 bacteria transformed with the empty vector were unable to grow on media lacking LTyrosine or L-Phenylalanine while all 50 transformants expressing the plant enzyme were able to grow on media lacking L-Tyrosine and L-Phenylalanine. For presentation purposes, only one control and one experimental transformant were used in the diagram. (b) shows the growth curve of the DL39 strain transformed with either pBAD33 (triangle) or pBAD33 + At5g36160 (circle) in M9 medium lacking LTyrosine and L-Phenylalanine supplemented with $0.2 \%(\mathrm{w} / \mathrm{v})$ arabinose. (c) shows the summary of the functional complementation assay of the plant enzyme ability to complement the E. coli triple mutant on M9 medium.

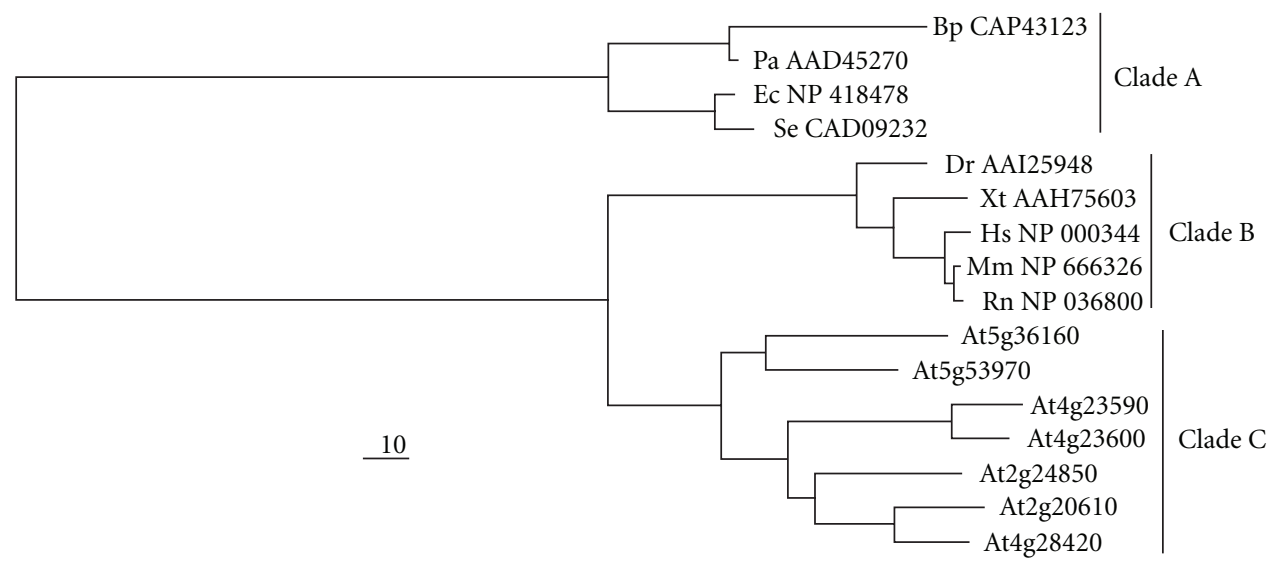

FIgURE 7: Phylogenetic tree depicting the evolutionary relationship between TATs from bacteria (Clade A), mammals (Clade B), and Arabidopsis (Clade C). The protein sequences were aligned using the ClustalW and the neighbor joining tree was constructed using the TREEVIEW software. 


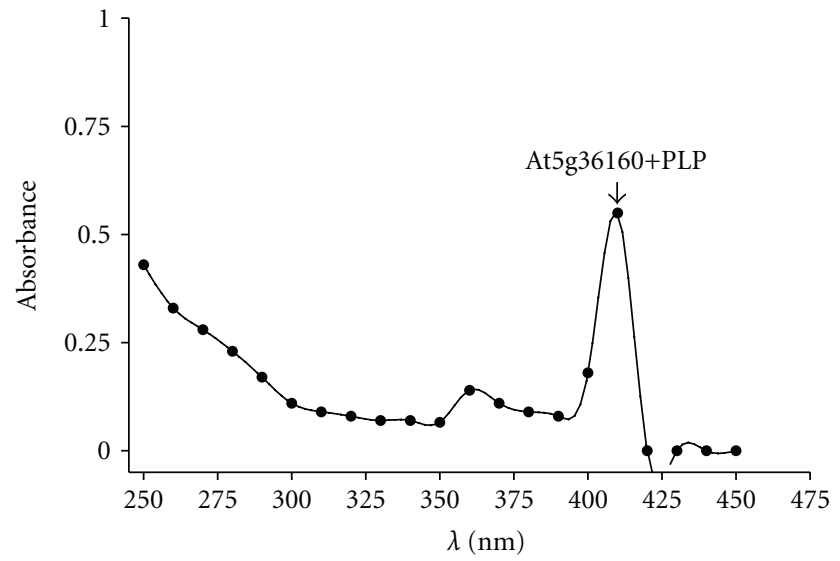

Figure 8: Absorption spectrum of At5g36160. UV-visible absorption spectrum of the native purified recombinant enzyme $(50 \mu \mathrm{g})$ in $100 \mathrm{mM}$ HEPES-NaOH ( $\mathrm{pH}$ 8.2). The PLP peak representing the PLP form of the enzyme is highlighted with an arrow.

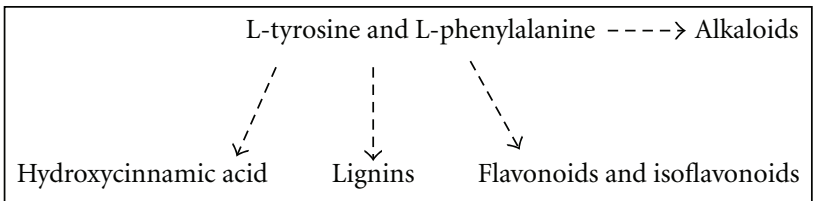

Figure 9: Secondary metabolites derived from the catabolism of L-Tyrosine and L-Phenylalanine in plants. The synthesis of secondary metabolites that are involved in plant defense occurs via the degradation of L-Tyrosine and L-Phenylalanine through the phenylpropanoid pathway.

the $K_{m}$ of the substrates using nonlinear regression analysis are provided as supplementary material (Figure 2).

3.8. Substrate Specificity. Aminotransferases are known to be promiscuous enzymes because conceptually, they catalyze the same reaction by transferring an amino group from a donor to an acceptor. We tested different acceptor compounds with the forward assay by using L-Tyrosine as the amino donor with 2-ketoglutarate, pyruvate, oxaloacetate, oxovalerate, or prephenate as the acceptors. The results from this analysis showed that the enzyme is not specific for 2ketoglutarate but is able to use other amino acceptors as a substrate although 2-ketoglutarate is the preferred substrate (Table 2(b)). The ability of At5g36160 to use different substrates with regards to amino donors was not a part of this study.

3.9. The Role of TAT in Plants. The de novo synthesis of LTyrosine and L-Phenylalanine occurs within the plastids of plants $[12,16]$. The subcellular localization of At5g36160 has not been demonstrated through experimentation. However, the enzyme is predicted to be localized in the cytosol by TargetP (http://www.cbs.dtu.dk/services/TargetP/) [34]. Plant TATs are more likely to be involved in the synthesis of secondary metabolites, given the fact that the enzyme is not necessary for L-Tyrosine and L-Phenylalanine synthesis in plants
TABLE 2: (a) Kinetic properties of At5g36160. The enzyme assays used to determine the kinetic parameters are described in Section 2. $V_{\max }$ is represented in $\mu$ moles $\mathrm{min}^{-1} \mathrm{mg}^{-1}$ of protein, $K_{m}$ of the various substrates is represented in millimolar $(\mathrm{mM})$, and $K_{\text {cat }}$ is represented in $\mathrm{S}^{-1}$. The measurements were made under optimal conditions with respect to $\mathrm{pH}$, temperature, and substrate concentrations (supplementary material). The kinetic constants were calculated by nonlinear regression analysis using the GraphPad Prism Version 3.03 software. (b) Relative substrate specificity of At5g36160 with various amino acceptors. The assay measured the production of 4-hydroxyphenylpyruvate at $331 \mathrm{~nm}$ using $10 \mathrm{mM}$ amino donor (L-Tyrosine) and $10 \mathrm{mM}$ amino acceptor.

(a)

\begin{tabular}{lcccc}
\hline Assay & $V_{\max }$ & $K_{\text {cat }}$ & Substrate & $K_{m}$ \\
\hline \multirow{3}{*}{ Forward $5 \pm 0.3$} & \multirow{2}{*}{0.08} & L-Tyrosine & $0.19 \pm 0.16$ \\
& & L-Phenylalanine & $0.84 \pm 0.2$ \\
& & 2-ketoglutarate & $1.2 \pm 0.27$ \\
\hline & & & L-Glutamate & $1.4 \pm 0.16$
\end{tabular}

Reverse $23.5 \pm 1.0$ 6.1 4-hydroxyphenylpyruvate $0.22 \pm 0.05$ Phenylpyruvate $\quad 0.13 \pm 0.06$

(b)

\begin{tabular}{lc}
\hline Acceptor/Donor combinations & Relative Activity (\%) \\
\hline L-Tyrosine/2-ketoglutarate & 100 \\
L-Tyrosine/oxaloacetate & 75 \\
L-Tyrosine/pyruvate & 40 \\
L-Tyrosine/prephenate & 23 \\
L-Tyrosine/oxovalerate & 3 \\
\hline
\end{tabular}

unless an unknown bacterial-like postchorismate pathway for the synthesis of L-Tyrosine and L-Phenylalanine exists in the cytoplasm of plants (Figures 1(a) and 1(b)). Moreover, secondary metabolites including alkaloids, lignins, flavonoids, isoflavonoids, and hydroxycinnamic acids are all derived from the phenylpropanoid catabolic pathway of LTyrosine and L-Phenylalanine (Figure 9) [35]. For example, 4-hydroxyphenylpyruvate is converted to homogentisate by the enzyme 4-hydoxyphenylpyruvate dioxygenase, which is the precursor compound for $\alpha$-tocopherol and plastoquinones. Secondary metabolites are synthesized by plants in response to biotic and abiotic stresses and these compounds have roles relating to mechanical strength, pollen viability, pest deterrence, UV protection, and disease resistance among others [35]. An example of secondary metabolite synthesis in response to biotic stress has been studied in Arabidopsis. Pseudomonas syringae produces the phytotoxin coronatine. Coronatine belongs to the polyketide class of secondary metabolites and it is an analog of octadecanoids (jasmonic acid or 12-oxo-phytodienoic acid). Typically, a chlorotic phenotype is observed when the plant is attacked by certain pathovars of $P$. syringae that synthesize coronatine [36]. However, in response to the phytotoxin, Arabidopsis produces and accumulates anthocyanins derived from the phenylpropanoid pathway [37, 38]. The production of flavonoids is important because they were shown to possess antioxidant properties which are involved in protection of 
the plant cells from free radicals [39]. Since coronatine was shown to upregulate the mRNA expression of the TAT gene annotated by the locus tag At4g23600 (Table 1) [6], we suspect that At5g36160 might have a similar role in plants. The involvement of aminotransferases in the plant defense response is not a new phenomenon. Two aminotransferases, AGD2 annotated by the locus tag At4g33680 and ALD1 annotated by the locus tag At2g13810 have been shown to be integral in the biosynthesis of a compound(s) that is involved in phytopathogen resistance or tolerance [40, 41]. Also, expression of a glyoxylate aminotransferase in Cucumis melo was shown to confer protection against Pseudoperonospora cubensis which is the cause of downy mildew in wild melons [42]. Our study does not address the question of whether At5g36160 is involved in plant defense response, but we envision future studies will address this topic by creating transgenic plants that overexpress TAT to address the question of phytopathogen tolerance to the bacteria $P$. syringae and by studying the effect(s) that exogenous coronatine and other phytotoxins have on the mRNA levels of TAT genes.

\section{Acknowledgments}

This work was supported by the School of Biological and Medical Sciences at RIT and by a Seed Funding Research Program Award from the Vice President of Research at RIT (AOH). Pranav R. Prabhu was supported by the Summer Undergraduate Research Program from the College of Science (RIT). The authors would like to thank Dr. Michael A. Savka for helpful comments.

\section{References}

[1] A. H. Liepman and L. J. Olsen, "Genomic analysis of aminotransferases in Arabidopsis thaliana," Critical Reviews in Plant Sciences, vol. 23, no. 1, pp. 73-89, 2004.

[2] P. K. Mehta, T. I. Hale, and P. Christen, "Aminotransferases: demonstration of homology and division into evolutionary subgroups," European Journal of Biochemistry, vol. 214, no. 2, pp. 549-561, 1993.

[3] A. O. Hudson, B. K. Singh, T. Leustek, and C. Gilvarg, "An LL-diaminopimelate aminotransferase defines a novel variant of the lysine biosynthesis pathway in plants," Plant Physiology, vol. 140, no. 1, pp. 292-301, 2006.

[4] A. J. McCoy, N. E. Adams, A. O. Hudson, C. Gilvarg, T. Leustek, and A. T. Maurelli, "LL-diaminopimelate aminotransferase, a trans-kingdom enzyme of a variant diaminopimelate/lysine synthesis enzyme shared by Chlamydia and plants," Proceedings of the National Academy of Sciences of the United States of America, vol. 103, no. 47, pp. 17909-17914, 2006.

[5] A. O. Hudson, C. Gilvarg, and T. Leustek, "Biochemical and phylogenetic characterization of a novel diaminopimelate biosynthesis pathway in prokaryotes identifies a diverged form of LL-diaminopimelate aminotransferase," Journal of Bacteriology, vol. 190, no. 9, pp. 3256-3263, 2008.

[6] A. Lopukhina, M. Dettenberg, E. W. Weiler, and H. HolländerCzytko, "Cloning and characterization of a coronatine- regulated tyrosine aminotransferase from Arabidopsis," Plant Physiology, vol. 126, no. 4, pp. 1678-1687, 2001.

[7] M. D. Mikkelsen, P. Naur, and B. A. Halkier, "Arabidopsis mutants in the C-S lyase of glucosinolate biosynthesis establish a critical role for indole-3-acetaldoxime in auxin homeostasis," Plant Journal, vol. 37, no. 5, pp. 770-777, 2004.

[8] C. Mavrides and W. Orr, "Multispecific aspartate and aromatic amino acid aminotransferases in Escherichia coli," Journal of Biological Chemistry, vol. 250, no. 11, pp. 4128-4133, 1975.

[9] D. H. Gelfand and R. A. Steinberg, "Escherichia coli mutants deficient in the aspartate and aromatic amino acid aminotransferases," Journal of Bacteriology, vol. 130, no. 1, pp. 429440, 1977.

[10] R. J. Whitaker, C. G. Gaines, and R. A. Jensen, "A multispecific quintet of aromatic aminotransferases that overlap different biochemical pathways in Pseudomonas aeruginosa," Journal of Biological Chemistry, vol. 257, no. 22, pp. 13550-13556, 1982.

[11] G. Byng, R. Whitaker, C. Flick, and R. A. Jensen, "Enzymology of l-tyrosine biosynthesis in corn (Zea Mays)," Phytochemistry, vol. 6, pp. 1289-1292, 1981.

[12] C. G. Gaines, G. S. Byng, R. J. Whitaker, and R. A. Jensen, "Ltyrosine regulation and biosynthesis via arogenate dehydrogenase in suspension-cultured cells of Nicotiana silvestris Speg. et Comes," Planta, vol. 156, no. 3, pp. 233-240, 1982.

[13] J. A. Connelly and E. E. Conn, "Tyrosine biosynthesis in Sorghum bicolor: isolation and regulatory properties of arogenate dehydrogenase," Zeitschrift fur Naturforschung, vol. 41, no. 1-2, pp. 69-78, 1986.

[14] C.A. Bonner, R. S. Fisher, R.R. Schmidt, P. W. Miller, and R. A. Jensen, "Distinct enzymes of aromatic amino acid biosynthesisthat are highly conserved in land plants are present in the chlorophytealga Chlorella sorokiniana," Plant Cell Physiol, vol. 36, pp. 1013-1022, 1995.

[15] H. Bickel, L. Plame, and G. Schultz, "Incorporation of shikimate and other precursors into aromatic amino acids and preylquinones of isolated spinach chloroplasts," Phytochemistry, vol. 17, pp. 119-124, 1978.

[16] M. Benesova and R. Bode, "Chorismate mutase isoforms from seeds and seedlings of Papaver somniferum," Phytochemistry, vol. 31, no. 9, pp. 2983-2987, 1992.

[17] T. A. d'Amato, R. J. Ganson, C. G. Gaines, and R. A. Jensen, "Subcellular localization of chorismate-mutase isoenzymes in protoplasts from mesophyll and suspension-cultured cells of Nicotiana silvestris," Planta, vol. 162, no. 2, pp. 104-108, 1984.

[18] J. Eberhard, E. Thomas, E. Petra et al., "Cytosolic and plastidic chorismate mutase isozymes from Arabidopsis thaliana: molecular characterization and enzymatic properties," Plant Journal, vol. 10, no. 5, pp. 815-821, 1996.

[19] P. Rippert, J. Puyaubert, D. Grisollet, L. Derrier, and M. Matringe, "Tyrosine and phenylalanine are synthesized within the plastids in Arabidopsis," Plant Physiology, vol. 149, no. 3, pp. 1251-1260, 2009.

[20] L.-M. Guzman, D. Belin, M. J. Carson, and J. Beckwith, "Tight regulation, modulation, and high-level expression by vectors containing the arabinose $\mathrm{P}(\mathrm{BAD})$ promoter," Journal of Bacteriology, vol. 177, no. 14, pp. 4121-4130, 1995.

[21] D. M. LeMaster and F. M. Richards, "NMR sequential assignment of Escherichia coli thioredoxin utilizing random fractional deuteriation," Biochemistry, vol. 27, no. 1, pp. 142$150,1988$.

[22] M. M. Bradford, "A rapid and sensitive method for the quantitation of microgram quantities of protein utilizing the principle of protein dye binding," Analytical Biochemistry, vol. 72, no. 1-2, pp. 248-254, 1976. 
[23] W. Gu, G. Zhao, C. Eddy, and R. A. Jensen, "Imidazole acetol phosphate aminotransferase in Zymomonas mobilis: molecular genetic, biochemical, and evolutionary analyses," Journal of Bacteriology, vol. 177, no. 6, pp. 1576-1584, 1995.

[24] L. Goodstadt and C. P. Ponting, "CHROMA: consensusbased colouring of multiple alignments for publication," Bioinformatics, vol. 17, no. 9, pp. 845-846, 2001.

[25] R. D. M. Page, "Treeview: an application to display phylogenetic trees on personal computers," Computer Applications in the Biosciences, vol. 12, no. 4, pp. 357-358, 1996.

[26] W. Gu, J. Song, C. A. Bonner, G. Xie, and R. A. Jensen, "PhhC is an essential aminotransferase for aromatic amino acid catabolism in Pseudomonas aeruginosa," Microbiology, vol. 144, no. 11, pp. 3127-3134, 1998.

[27] P. K. Mehta, T. I. Hale, and P. Christen, "Evolutionary relationships among aminotransferases. Tyrosine aminotransferase, histidinol-phosphate aminotransferase, and aspartate aminotransferase are homologous proteins," European Journal of Biochemistry, vol. 186, no. 1-2, pp. 249-253, 1989.

[28] R. A. Jensen and W. Gu, "Evolutionary recruitment of biochemically specialized subdivisions of family I within the protein superfamily of aminotransferases," Journal of Bacteriology, vol. 178, no. 8, pp. 2161-2171, 1996.

[29] T. S. Lu and M. Mazelis, "L-ornithine 2-oxoacid aminotransferase from squash cotyledons," Plant Physiology, vol. 55, pp. 502-506, 1975.

[30] E. Ryan and P. F. Fottreell, "Interactions between an unusual aspartate amiontransferase from Rhizobium japonicum and pyridoxal-5'-phosphate studied by affinity," FEBS Letters, vol. 23, pp. 73-76, 1972.

[31] T.-P. Ko, S.-P. Wu, W.-Z. Yang, H. Tsai, and H. S. Yuan, "Crystallization and preliminary crystallographic analysis of the Escherichia coli tyrosine aminotransferase," Acta Crystallographica, vol. D55, no. 8, pp. 1474-1477, 1999.

[32] R. A. John, "Pyridoxal phosphate-dependent enzymes," Biochimica et Biophysica Acta, vol. 1248, no. 2, pp. 81-96, 1995.

[33] N. Watanabe, M. M. Cherney, M. J. van Belkum et al., "Crystal structure of ll-diaminopimelate aminotransferase from Arabidopsis thaliana: a recently discovered enzyme in the biosynthesis of l-lysine by plants and Chlamydia," Journal of Molecular Biology, vol. 371, no. 3, pp. 685-702, 2007.

[34] O. Emanuelsson, S. Brunak, G. von Heijne, and H. Nielsen, "Locating proteins in the cell using TargetP, SignalP and related tools," Nature Protocols, vol. 2, no. 4, pp. 953-971, 2007.

[35] R. B. Nair, K. L. Bastress, M. O. Ruegger, J. W. Denault, and C. Chapple, "The Arabidopsis thaliana reduced epidermal fluorescencel gene encodes an aldehyde dehydrogenase involved in ferulic acid and sinapic acid biosynthesis," Plant Cell, vol. 16, no. 2, pp. 544-554, 2004.

[36] S. S. Gnanamaickam, A. N. Starratt, and E. W. B. Ward, "Coronatine production in vitro and in vivo and its relation to symptom development in bacterial blight of soybean," Canadian Journal of Botany, vol. 60, pp. 645-650, 1982.

[37] A. F. Bent, R. W. Innes, J. R. Ecker, and B. J. Staskawicz, "Disease development in ethylene-insensitive Arabidopsis thaliana infected with virulent and avirulent Pseudomonas and Xanthomonas pathogens," Molecular Plant-Microbe Interactions, vol. 5, no. 5, pp. 372-378, 1992.

[38] J.-M. Kong, L.-S. Chia, N.-K. Goh, T.-F. Chia, and R. Brouillard, "Analysis and biological activities of anthocyanins," Phytochemistry, vol. 64, no. 5, pp. 923-933, 2003.

[39] H. Wang, G. Cao, and R. L. Prior, "Oxygen radical absorbing capacity of anthocyanins," Journal of Agricultural and Food Chemistry, vol. 45, no. 2, pp. 304-309, 1997.
[40] J. T. Song, H. Lu, and J. T. Greenberg, "divergent roles in arabidopsis thaliana development and defense of two homologous genes, abberant growth and death2 and AGD2like defense response protein1, encoding novel aminotransferases," Plant Cell, vol. 16, pp. 353-366, 2004.

[41] J. T. Song, H. Lu, J. M. McDowell, and J. T. Greenberg, “A key role for ALD1 in activation of local and systemic defenses in Arabidopsis," Plant Journal, vol. 40, no. 2, pp. 200-212, 2004.

[42] D. Taler, M. Galperin, I. Benjamin, Y. Cohen, and D. Kenisgsbuc, "Plant enzymatic resistance (eR) genes encoding for photorespiratory enzymes confer resistance against disease," Plant Cell, vol. 16, pp. 172-184, 2004. 

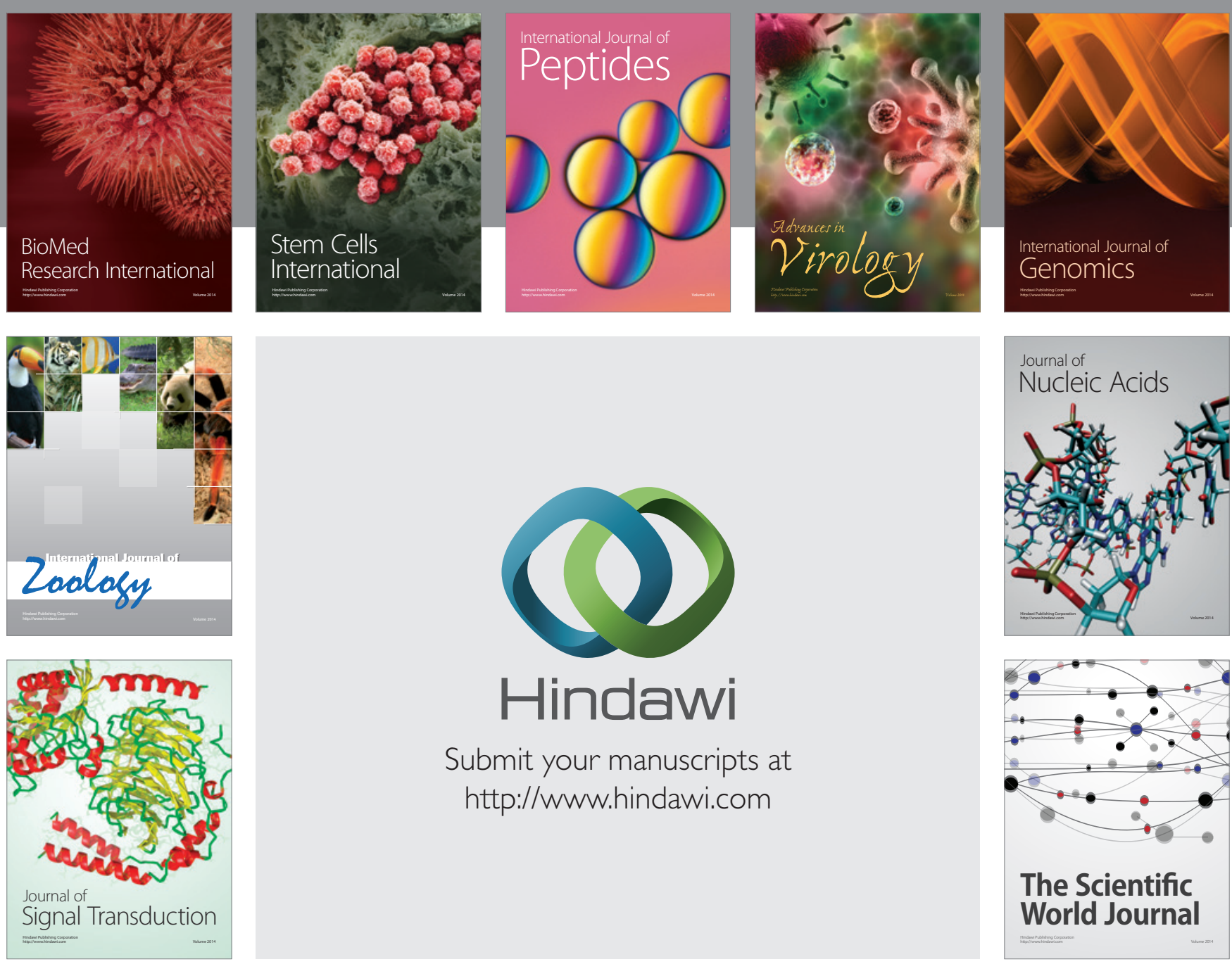

Submit your manuscripts at

http://www.hindawi.com
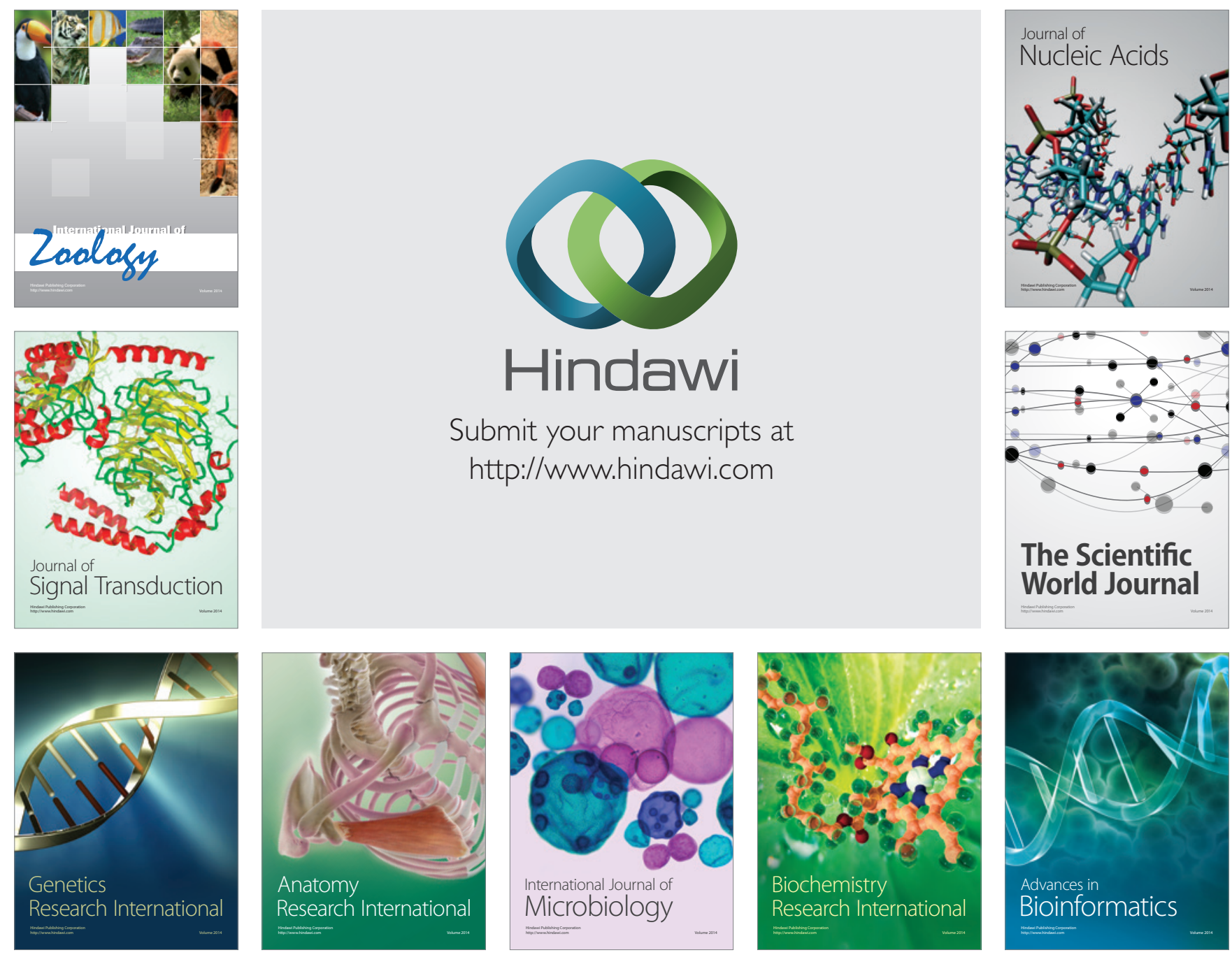

The Scientific World Journal
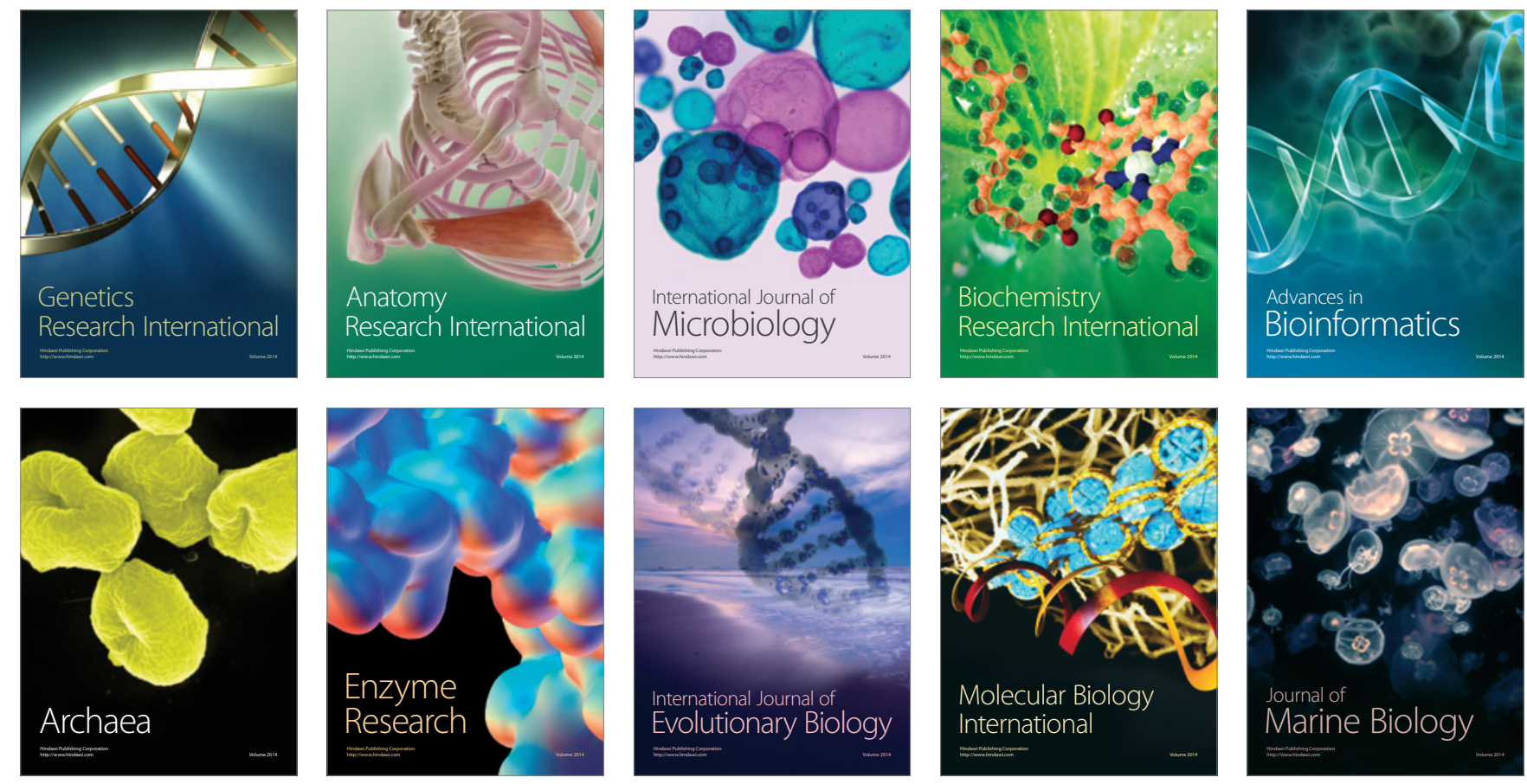